\title{
Schwann cell myelination requires Dynein function
}

\author{
Melissa M Langworthy and Bruce Appel
}

\begin{abstract}
Background: Interaction of Schwann cells with axons triggers signal transduction that drives expression of Pouzf1 and Egr2 transcription factors, which in turn promote myelination. Signal transduction appears to be mediated, at least in part, by cyclic adenosine monophosphate (CAMP) because elevation of CAMP levels can stimulate myelination in the absence of axon contact. The mechanisms by which the myelinating signal is conveyed remain unclear.
\end{abstract}

Results: By analyzing mutations that disrupt myelination in zebrafish, we learned that Dynein cytoplasmic 1 heavy chain 1 (Dync1h1), which functions as a motor for intracellular molecular trafficking, is required for peripheral myelination. In dync1h1 mutants, Schwann cell progenitors migrated to peripheral nerves but then failed to express Pou3f1 and Egr2 or make myelin membrane. Genetic mosaic experiments revealed that robust Myelin Basic Protein expression required Dync1h1 function within both Schwann cells and axons. Finally, treatment of dyncih1 mutants with a drug to elevate cAMP levels stimulated myelin gene expression.

Conclusion: Dync1h1 is required for retrograde transport in axons and mutations of Dync1h1 have been implicated in axon disease. Our data now provide evidence that Dync1h1 is also required for efficient myelination of peripheral axons by Schwann cells, perhaps by facilitating signal transduction necessary for myelination.

Keywords: Glia, Peripheral nerve, Dync1h1, Zebrafish, Myelin

\section{Background}

Motor control and sensation require that nerve impulses are rapidly and efficiently transmitted over long distances. This is achieved by axons, which relay electrical signals between the central nervous system and peripheral muscles and sensory elements, and Schwann cells, which enhance the speed and efficiency of signal propagation by ensheathing peripheral axons with insulating myelin. Peripheral nerves can be very long, reaching more than $1 \mathrm{~m}$ in humans, but elaboration of a farreaching peripheral nerve network comes with an apparent cost in that it is highly susceptible to disease. More than 100 kinds of peripheral neuropathy affecting motor, sensory and autonomic systems, and numerous degenerative diseases that attack, in particular, motor neurons, have been described.

Investigation of the molecular mechanisms of peripheral nerve disease has revealed that disruption of axon

\footnotetext{
*Correspondence: bruce.appel@ucdenver.edu

Departments of Pediatrics and Cell and Developmental Biology, University of Colorado School of Medicine, MS 8108, Aurora, CO 80045, USA
}

transport can cause nerve dysfunction and degeneration [1]. Molecular transport in healthy axons requires microtubules upon which cargo is carried, Kinesins, motors that generally move cargo from the neuron soma toward the axon tips, and Dynein cytoplasmic 1 heavy chain 1 (Dync1h1), which moves cargo in the opposite, retrograde direction. Disruption of any one of these components can cause disease. For example, a missense mutation that changes an amino acid within the homodimerization domain of Dync1h1 has been found in affected members of a family diagnosed with a dominant, axonal form of Charcot-Marie-Tooth (CMT) Disease [2] that is characterized by distal muscle weakness and atrophy, and mutations of the $\mathrm{p} 150^{\text {Glued }}$ subunit of Dynactin, which interacts with Dync1h1, have been identified in families with slowly progressive lower motor neuron disease and amyotrophic lateral sclerosis [3,4]. Furthermore, dominant mutations of Dync1h1 that cause loss of proprioceptive sensory neurons have been identified in mice [5-7]. Whether disruption of Dynein-mediated
C Bïomed Central

(C) 2012 Langworthy and Appel; licensee BioMed Central Ltd. This is an Open Access article distributed under the terms of the Creative Commons Attribution License (http://creativecommons.org/licenses/by/2.0), which permits unrestricted use,

distribution, and reproduction in any medium, provided the original work is properly cited. 
molecular transport in other cellular components of peripheral nerves contributes to disease is not known.

Through a forward genetic approach using zebrafish, we found that Dync1h1 function is essential for peripheral myelination. Schwann cells were present at peripheral axons in dync1h1 mutant larvae but did not wrap them with multiple layers of membrane or express myelin genes. Genetic mosaic experiments revealed that, in addition to its role in axon transport, Dync1h1 is required in Schwann cells for efficient myelination. Deficits in peripheral myelin were improved by stimulating cAMP level, which normally mediates axon signaling necessary for myelination, raising the possibility that transduction of the myelination signal requires Dync1h1-mediated molecular transport. These insights indicate that disruption of molecular transport mechanisms might contribute to peripheral disease by affecting both axons and Schwann cells.

\section{Results}

dync1h1 function is essential for Schwann cell myelin basic protein expression

In a forward genetic screen for mutations that disrupt glial development, we identified an allele of dync1h1 that caused both central nervous system (CNS) and peripheral nervous system (PNS) myelination defects. The CNS and PNS defects were distinct from each other, therefore, we report here only an investigation of the PNS phenotype, using the previously identified dync1h $1^{h i 3684 T g}$ mutant allele [8], which has a retroviral insertion at intron 52 [9]. The new allele and its associated CNS phenotype will be reported elsewhere. To assess myelination, we first used in situ hybridization to detect expression of myelin basic protein $(m b p)$ RNA. At 4.25 days post fertilization (dpf), wild-type larvae expressed $m b p$ RNA in the spinal cord and along motor roots (Figure 1A) and at the posterior lateral line nerve (pLLn) (Figure 1B). By $6 \mathrm{dpf}$, immunohistochemistry revealed Mbp associated with motor axons (Figure 1C) and the pLLn (data not shown). By contrast, dync1h1 mutant larvae expressed $m b p$ RNA within the spinal cord (Figure 1D) but not along motor roots or the pLLn (Figure 1D, E). Consistent with the reduction of $m b p$ transcripts, very little Mbp was evident associated with peripheral axons in dync1h1 mutant larvae (Figure 1F, data not shown). Most wild-type larvae (101 of 108), injected with antisense morpholino oligonucleotides
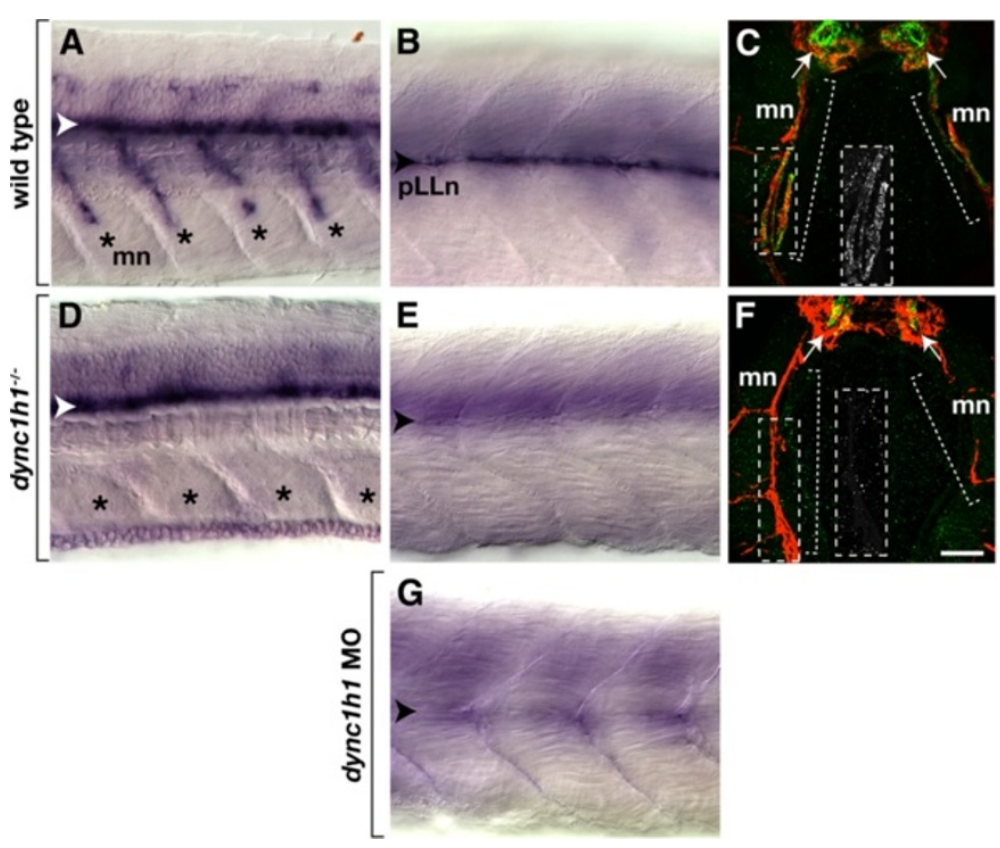

Figure 1 dync1h1-deficient larvae express mbp RNA and protein in the central nervous system (CNS) but not the peripheral nervous system (PNS). (A, B) mbp RNA expression in the ventral spinal cord (white arrowhead), along motor nerves (mn, asterisks) and at the posterior lateral line nerve (pLLn, black arrowhead) of wild-type larvae. (C) Immunohistochemistry reveals Mbp (green) associated with motor nerves marked by Acetylated Tubulin staining (red, brackets). Arrows indicate prominent Mbp in the ventral spinal cord. The inset shows Mbp expression, alone, of the portion of the motor nerve, indicated by the dashed box. (D, E) mbp RNA expression in the spinal cord but not at the motor nerves or the pLLn of dyncihl mutant larvae. (F) Mbp is absent from motor nerves and reduced in the ventral spinal cord of a mutant larva. The inset shows Mbp labeling, alone, of the portion of the motor nerve indicated by the dashed box. (G) pLLn of a wild-type larvae injected with dync1h1 antisense MO lacks mbp RNA expression. Panels A, B, D, E and $\mathbf{G}$ show whole 4.25 days post fertilization (dpf) larvae at the level of the mid-trunk with anterior to the left and dorsal to the top. Panels $\mathbf{C}$ and $\mathbf{F}$ show transverse sections through the level of the trunk with dorsal up. Scale bars equal $20 \mu \mathrm{m}(\mathbf{A}, \mathbf{B}, \mathbf{D}, \mathbf{E}, \mathbf{G}), 40 \mu \mathrm{m}(\mathbf{C}, \mathbf{F})$ and $50 \mu \mathrm{m}$ for the insets. 
(MO), which was designed to block translation of dync1h1 mRNA [9], also lacked $m b p$ expression (Figure 1G), confirming that the $m b p$ expression defect of mutant larvae resulted from disruption of the dync1h1 gene. Therefore, Dync1h1 function is essential for peripheral myelin gene expression.

dync1h1 mutant larvae might lack peripheral $m b p$ expression because they lack Schwann cells or because Schwann cells fail to differentiate. To distinguish between these possibilities we examined Sox10 expression, which marks Schwann cell progenitors [10,11]. Similar to wild-type larvae, Sox $10^{+}$cells were close to both motor axons and pLLn axons in dync1h1 mutant larvae (Figure 2A, B). In fact, more Sox $10^{+}$cells were associated with motor axons in dync1h1 mutant larvae than wild type at 2, 3 and $4 \mathrm{dpf}$ (Figure $2 \mathrm{C}$ ). The number of Sox $10^{+}$cells at the pLLn did not differ between wild type and mutant at 2 and $3 \mathrm{dpf}$, however, Sox $10^{+}$cells did not increase in dync1h1 mutant larvae between 3 and $4 \mathrm{dpf}$, resulting in a deficit relative to wild type (Figure 2D). We conclude that the absence of peripheral $m b p$ expression in dync1h1 mutant larvae does not result from an absence of Schwann cells. Therefore, lack of $m b p$ expression is consistent with the possibility that Schwann cells fail to differentiate in mutant larvae.

We next examined the behavior of Schwann cell progenitors using time-lapse imaging. In wild-type $\operatorname{Tg}$ (sox10: mRFP) embryos, which express membrane-tethered RFP under control of sox10 regulatory DNA [12], neural crest-derived Schwann cell progenitors converged near motor axon exit points (MEPs) and migrated in chainlike fashion along motor roots (Figure 3A). Schwann cell progenitors moved slower and less directly toward MEPs in dync1h1 mutant embryos than in wild type (Figure 3B-F). Nevertheless, Schwann cell progenitors consistently arrived at and migrated along motor roots. We did not observe abnormal migration of Schwann cell progenitors at the pLLn (data not shown). These data show that the lack of $m b p$ expression in dync1h1 mutant larvae does not result from absence of Schwann cells. Instead, dync1h1 function must be necessary for Schwann cell differentiation.
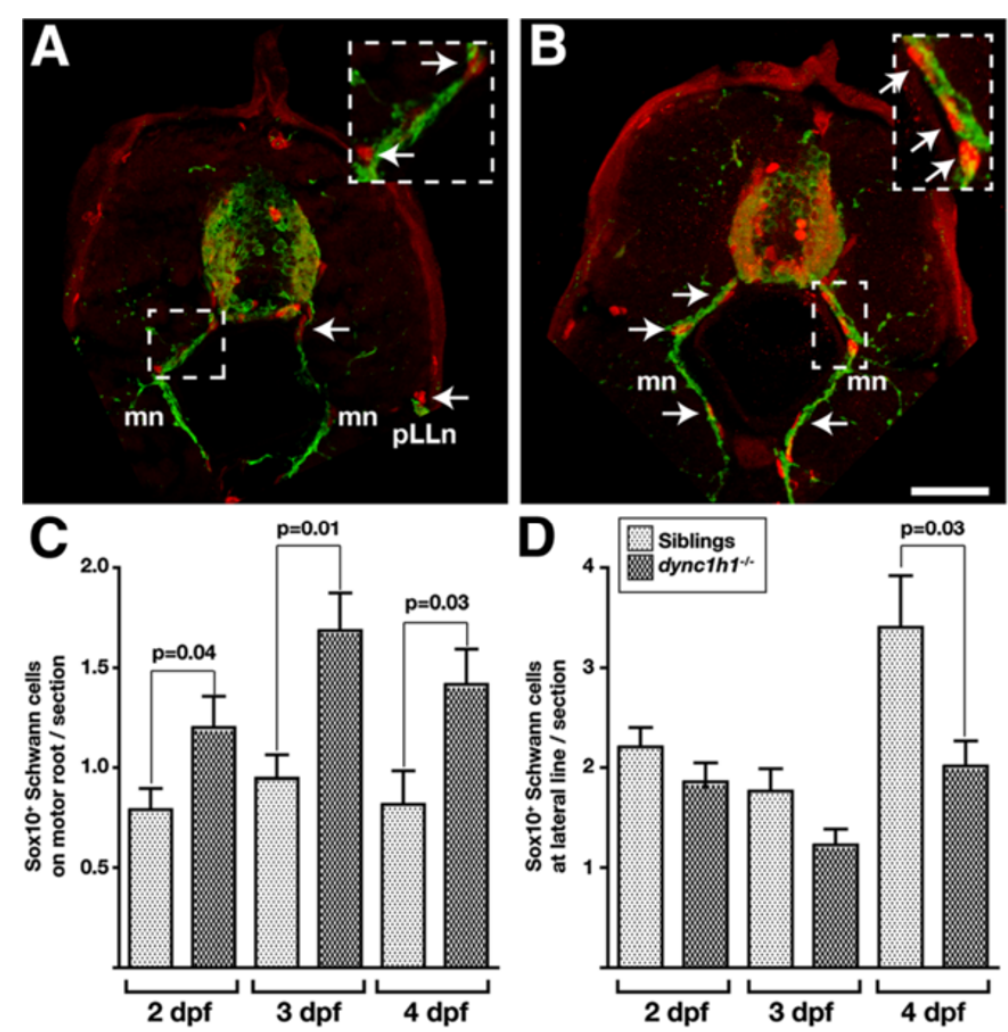

Figure 2 Schwann cells are present at peripheral nerves in dync1h1 mutant larvae. (A, B) Images of transverse sections at the level of the mid-trunk of $3 \mathrm{dpf}$ wild-type (A) and dync1h1 mutant (B) larvae labeled with antibodies to reveal Sox10 (red) and acetylated tubulin (green), which mark Schwann cells and axons, respectively. Schwann cells (arrows) are close to axons of motor nerves (mn) and the posterior lateral line nerve (pLLn). Insets are higher magnification views of motor nerves indicated by the dashed boxes. (C, D) Quantification of Schwann cells associated with motor roots (C) and pLLn (D). Significance of differences in Sox $10^{+}$Schwann cell numbers were calculated using nonparametric Mann-Whitney $U$ analysis. Error bars represent standard error of the mean (SEM). Scale bar equals $80 \mu \mathrm{m}$ for the main panel and $40 \mu \mathrm{m}$ for the insets. 

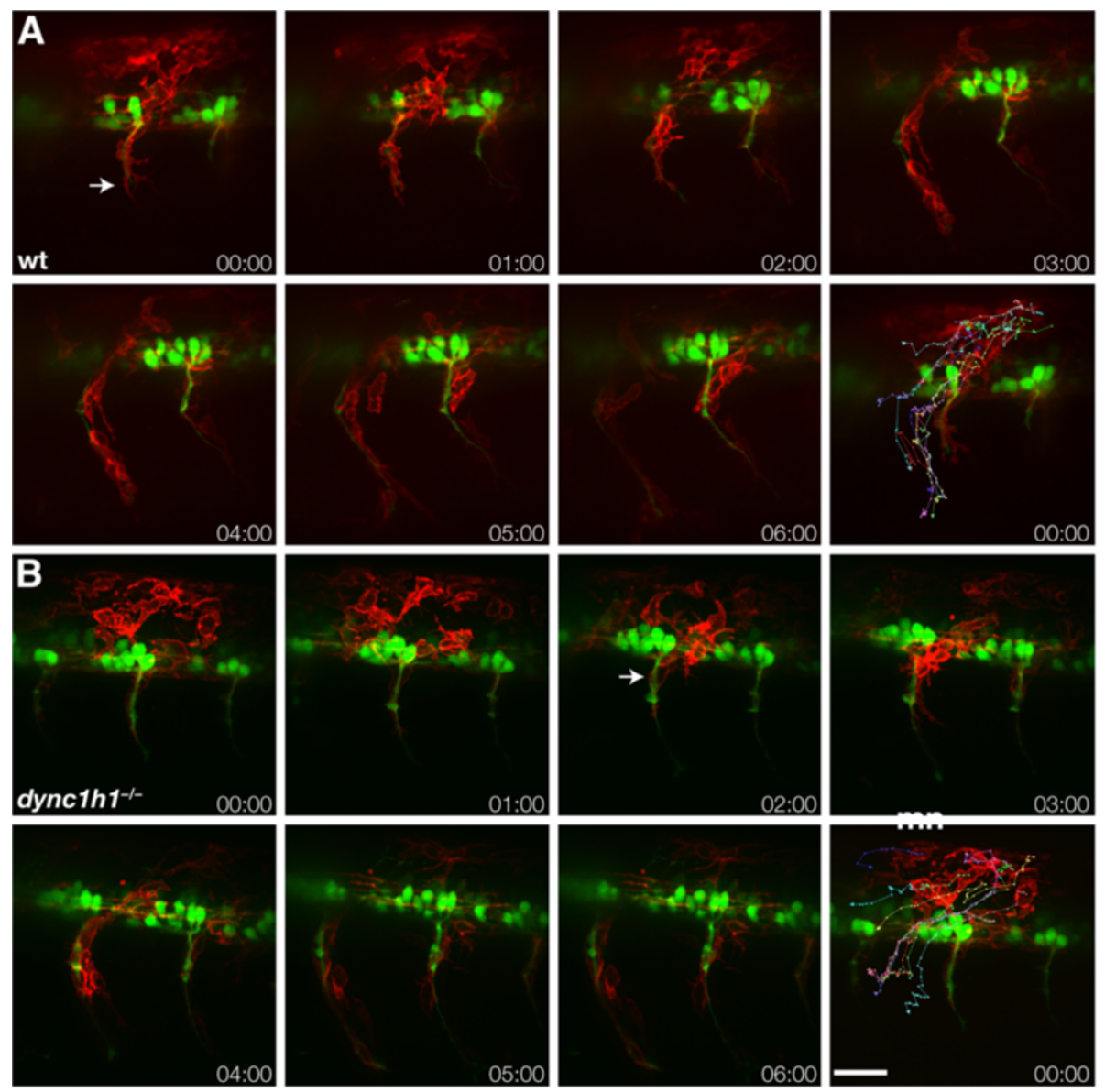

C

D
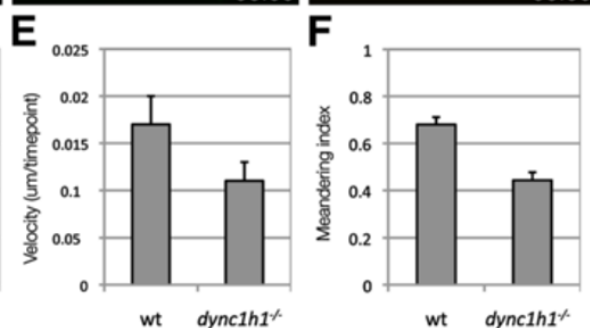

Figure 3 Schwann cells migrate to motor axons in dync1h1 mutant larvae. (A, B) Frames from time-lapse movies of wild-type (A) and dync1h1 mutant (B) larvae carrying Tg(sox10:mRFP) and Tg(mnx1:GFP) transgenes to mark Schwann cells (red, arrow) and motor axons (green). Each sequence starts at 20 hours post fertilization (hpf) and elapsed time is shown in each panel. The final panel in each series shows tracks plotted for the migration of ten RFP ${ }^{+}$Schwann cells over 6 hours, with 10 time points per hour. Images shown are lateral views of mid-trunk spinal cord with dorsal up. (C-F) Quantification of Schwann cell progenitor migration. The migration of ten sox10:mRFP ${ }^{+}$Schwann cells were tracked over 6 hours with 10 time points per hour. (C) Schwann cell trajectories were assigned a direction of movement based on their starting and ending positions where the apex was assigned as the motor root exit point. I corresponds to anterior to posterior migration, II corresponds to dorsal to ventral migration, and III indicates posterior to anterior Schwann cell migration. A representative track from a wild-type embryo is displayed. (D) Quantification of Schwann cell trajectories from three embryos (30 Schwann cells) indicates that migration to the motor root is reduced but not eliminated in dync1h1 mutants. Categories I, II and III correspond to the diagram in panel C. No MR represents the Schwann cells that did not reach the motor root. (E) Schwann cell velocity is reduced in dync $1 \mathrm{~h} 1^{-1-}$ embryos $(P=0.004)$. (F) Schwann cell meandering index, calculated by the displacement from the origin by the track length, is reduced in dync $1 h 1^{-/-}$embryos $(P<0.0001)$ indicating less directed movement. $P$-values were calculated for each track using nonparametric Mann-Whitney U-test statistical analysis. Error bars represent standard error of the mean (SEM). Scale bar equals $40 \mu \mathrm{m}$.

\section{dync1h1 function is required for axon wrapping and} myelination

Although the above data show that Schwann cells were close to peripheral nerves in dync1h1 mutant larvae it was not apparent whether they wrapped axons. We investigated the structure of peripheral nerves by examining Schwann cell morphologies revealed by transgenic reporter gene expression. Motor axons of wild-type larvae, 
marked by $\operatorname{Tg}(m n x 1: G F P)$ expression [13], were ensheathed by tube-like sox10:mRFP ${ }^{+}$Schwann cells, which expressed Mbp (Figure 4A). By contrast, Schwann cells with tube-like morphologies and Mbp expression were not evident in dync1h1 mutant larvae and Schwann cells appeared to have loose contact with axons (Figure 4B). We also examined Schwann cells at the pLLn marked by sox10:mRFP expression in combination with immunohistochemistry to reveal axons. Whereas many tubular $\mathrm{Mbp}^{+}$Schwann cells were evident at the pLLn of wildtype larvae (Figure 4C), in dync1h1 mutant larvae Schwann cells, which did not express Mbp, appeared more loosely associated with the nerve (Figure 4D). Additionally, whereas motor axon bundles were similar in wild-type and mutant larvae (Figures 1C, F, 2A, B, 4A, B), the pLLn of mutant larvae appeared to have fewer axons than wild type (Figure 4C, D).

\section{Dync1h1 function within Schwann cells promotes myelination}

A failure of myelination in dync1h1 mutant larvae could result from a defect in either axons or Schwann cells or in both axons and Schwann cells. For example, dync $1 h 1^{-/-}$axons might not provide a myelination signal to Schwann cells or mutant Schwann cells might not receive or transduce a myelination signal from axons. To distinguish between these possibilities we used cell transplantation to create genetic mosaic larvae. To investigate if wild-type Schwann cells can activate expression of Mbp when associated with $d y n c 1 h 1$ mutant neurons, we transplanted at blastula stage, cells from wild-type $T g$ (sox10:mRFP) embryos labeled with Alexa488-conjugated dextran, to nontransgenic embryos produced by matings of $d y n c 1 h 1^{+/-}$adults. In this experiment the dextran label allowed us to select mutant host larvae that had

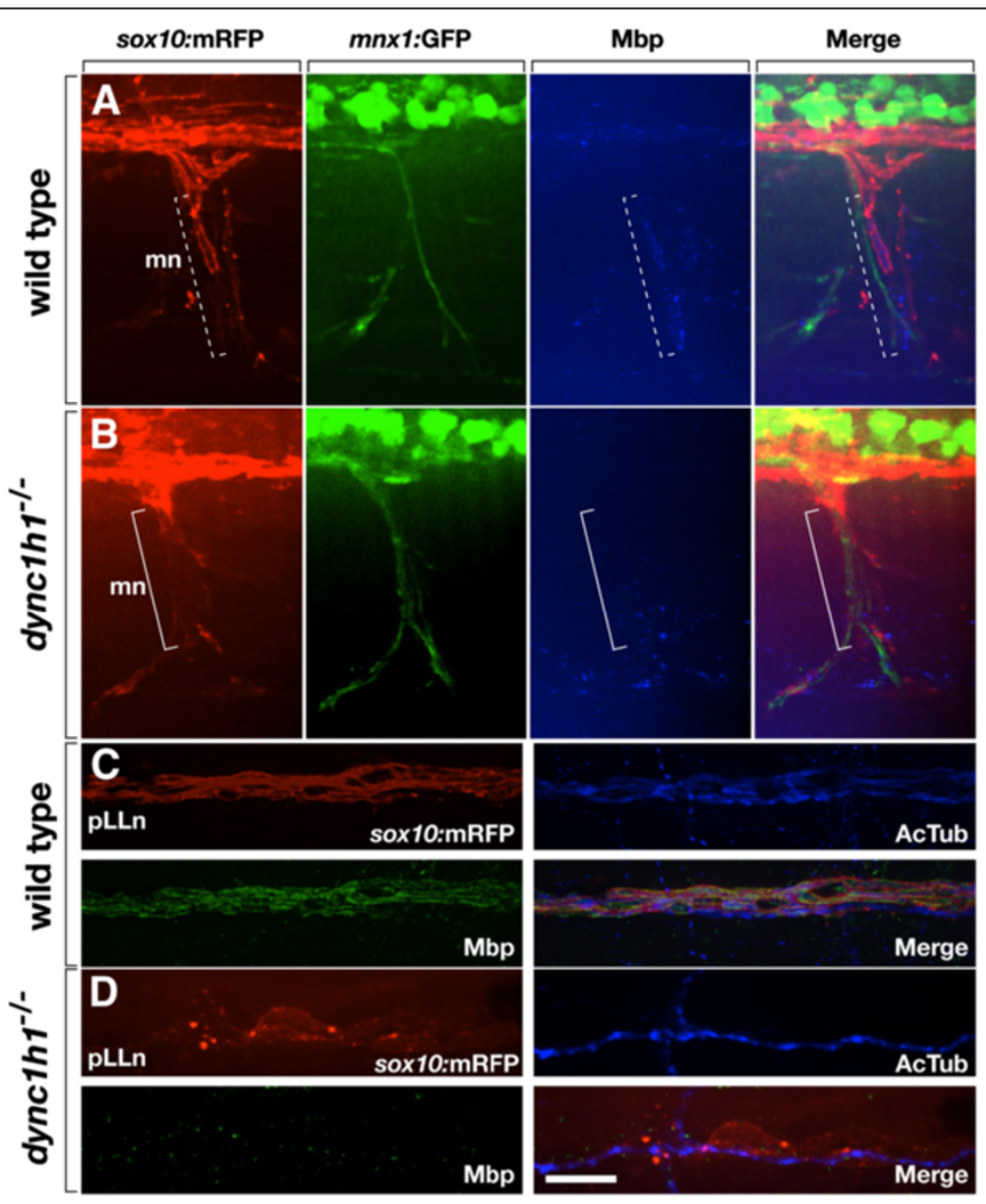

Figure 4 Loss of dync1h1 function disrupts axon wrapping and Mbp expression by Schwann cells. (A, B) Wild-type and dyncih1 mutant larvae expressing sox10:mRFP (red) and mnx1:GFP (green) and labeled by anti-Mbp antibody (blue). Tube-like Mbp ${ }^{+}$Schwann cells are evident at some axons of the motor nerve (mn) in wild type (dashed bracket) whereas Mbp- Schwann cells appear more loosely associated with axons in the mutant (solid bracket). (C, D) Wild-type and dync1h1 mutant larvae expressing sox10:mRFP (red) and labeled by anti-Mbp (green) and antiacetylated tubulin (AcTub, blue) antibodies. Mbp ${ }^{+}$Schwann cells ensheath pLLn axons in wild-type. By contrast, RFP ${ }^{+}$Schwann cells associated

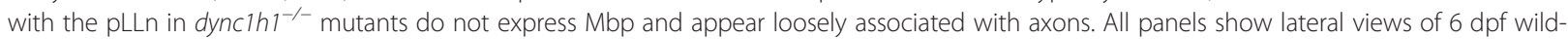

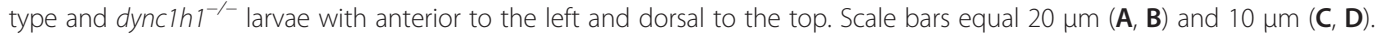


peripheral nerves containing wild-type Schwann cells but not wild-type axons. These were then processed for immunohistochemistry to detect $\mathrm{Mbp}$ at $5 \mathrm{dpf}$. At both the pLLn (Figure 5A) and motor nerves (Figure 5B) of dync1h1 mutant larvae, wild-type Schwann cells wrapped mutant axons normally and expressed $\operatorname{Mbp}(\mathrm{n}=9$ and $\mathrm{n}=14$ larvae, respectively). We also performed the reciprocal experiment whereby we transplanted cells from blastula stage $\operatorname{Tg}(\operatorname{sox} 10: m R F P)$ embryos injected with dync1h1 MO to wild-type embryos. Although we could identify transplanted cells within the premigratory neural crest population, we never found them associated with motor nerves during the normal period of myelination. We found a few transplanted, dync1h1-deficient cells at the pLLn, however, these had abnormal morphologies and occupied very narrow spaces between neighboring wild-type Schwann cells (data not shown). We speculate that dync1h1-deficient Schwann cells are at a competitive disadvantage for positions on peripheral axons when mixed with wild-type Schwann cells.

To investigate if mutant Schwann cells can express myelin in the presence of wild-type axons, we transplanted at blastula stage, cells from wild-type $\mathrm{Tg}$ (elavl3: Kaede) embryos, to embryos produced by matings of
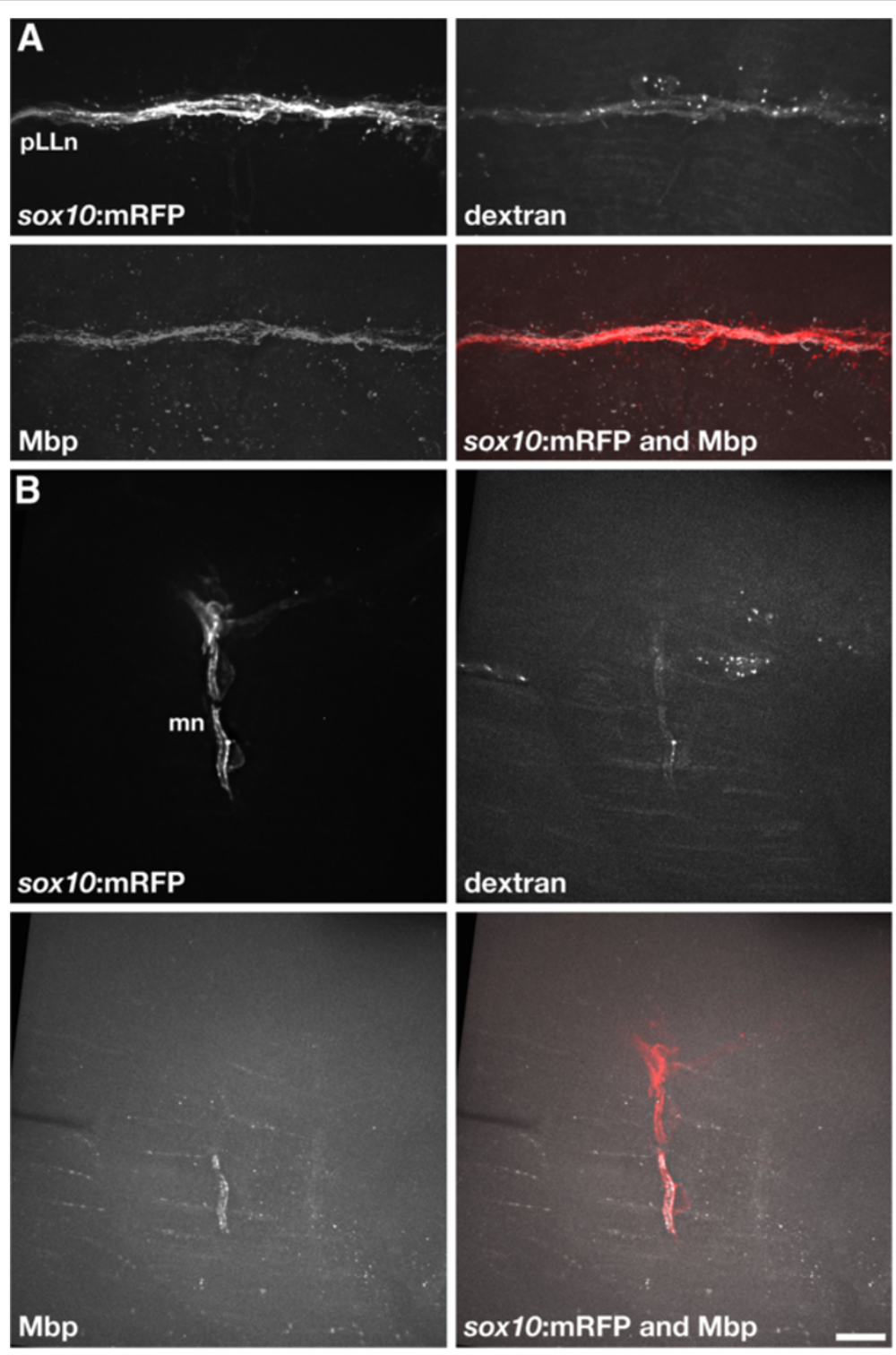

Figure 5 Wild-type Schwann cells express Mbp when associated with dync1h1 mutant axons. (A) Transplanted wild-type Alexa488-dextran ${ }^{+}$ sox 10:mRFP ${ }^{+}$Schwann cells associated with pLLn axons of a $5 \mathrm{dpf}$ dync1h1 mutant host larva. The transplanted Schwann cells expressed Mbp, detected by immunohistochemistry. (B) Two transplanted wild-type Alexa488-dextran ${ }^{+}$sox 10:mRFP ${ }^{+}$Schwann cells associated with motor axons of a dync1h1 mutant host larva. One of the two transplanted Schwann cells expressed Mbp. Scale bar equals $10 \mu \mathrm{m}$. 
$\operatorname{Tg}(\operatorname{sox} 10: m R F P) ; d y n c 1 h 1^{+/-}$adults. In this experiment, we could recognize any mutant host larvae with wildtype donor motor and pLLn axons labeled by elavl3: Kaede expression. We analyzed a total of 16 mutant host larvae that had wild-type elav3:Kaede ${ }^{+}$pLLn axons associated with mutant sox 10:mRFP ${ }^{+}$Schwann cells. In $75 \%$ of these chimeric larvae ( $\mathrm{n}=12$ of 16 ), mutant sox10:mRFP ${ }^{+}$Schwann cells associated with wild-type axons had normal wrapping morphologies but apparently only low levels of Mbp, localized in a punctate pattern (Figure 6A). In the remaining $25 \%$ of these host larvae
( $\mathrm{n}=4$ of 16), mutant Schwann cells associated with wild-type axons appeared to express and localize Mbp normally (Figure 6B). We also found two mutant host larvae that had pLL nerves consisting of both wild-type axons and wild-type Schwann cells, inferred by the absence of sox10:mRFP expression; these appeared to express Mbp normally (Figure 6C). Additionally, three mutant host larvae had mutant Schwann cells associated with motor nerves that contained wild-type axons; these Schwann cells neither wrapped axons nor expressed Mbp (data not shown). Taken together, our genetic mosaic
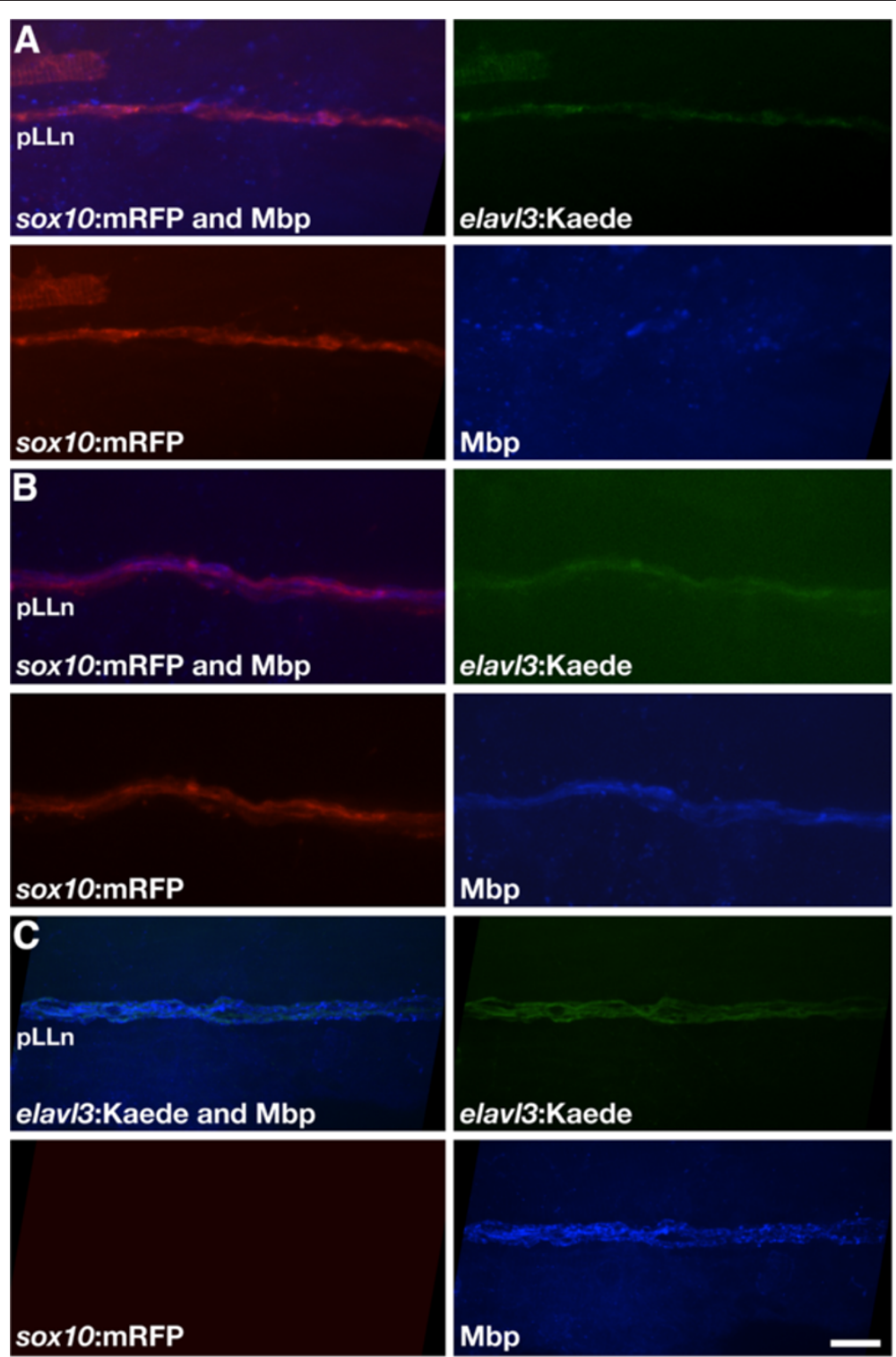

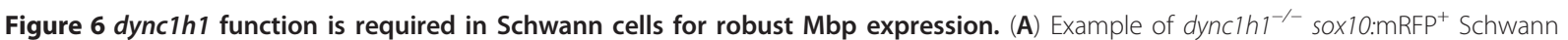
cells (red) expressing Mbp (blue) at low or undetectable levels when associated with transplanted wild-type elav/3:Kaede ${ }^{+}$pLLn axons (green).

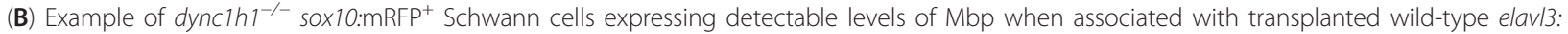
Kaede $^{+}$pLLn axons. (C) Example of transplanted wild-type Schwann cells expressing Mbp when associated with transplanted wild-type pLLn axons in a dync1h1 mutant host larva. Scale bar equals $10 \mu \mathrm{m}$. 
data indicate that $d y n c 1 h 1$ functions in Schwann cells to promote myelination because wild-type Schwann cells can express Mbp when in contact with axons lacking dync1h1. However, they also indicate that the dync1h1 is not absolutely required in Schwann cells for myelination because mutant Schwann cells can sometimes express Mbp when associated with wild-type axons. Therefore, efficient and robust myelination appears to require dync1h1 function in both Schwann cells and neurons.

\section{dync $1 \mathrm{~h} 1$ function is required for Schwann cell differentiation}

Our data show that in the absence of dync1h1 function, Schwann cell progenitors migrate to peripheral axons but fail to ensheath them normally or express a myelin gene. This raised the possibility that Schwann cells require $d y n c 1 h 1$ to progress from a progenitor state to a mature, myelinating state. To test this hypothesis, we investigated expression of genes that characterize distinct stages of Schwann cell differentiation [14]. Consistent with immunohistochemistry data described above, sox10 RNA expression, which marks neural crest cells and Schwann cell progenitors, was similar in wild-type and dync1h1 mutant larvae (Figure 7A, B). Although Schwann cells associated with the pLLn expressed $e r b b 3 b$, which encodes a receptor necessary for Schwann cell development [15], only very weakly (data not shown), motor root Schwann cells expressed it robustly, with no difference evident between wild-type and dync1h1 mutant embryos (Figure 7C, D). Expression of foxd 3 and tfap $2 a$, which encode transcription factors that function in the early Schwann cell lineage $[16,17]$,

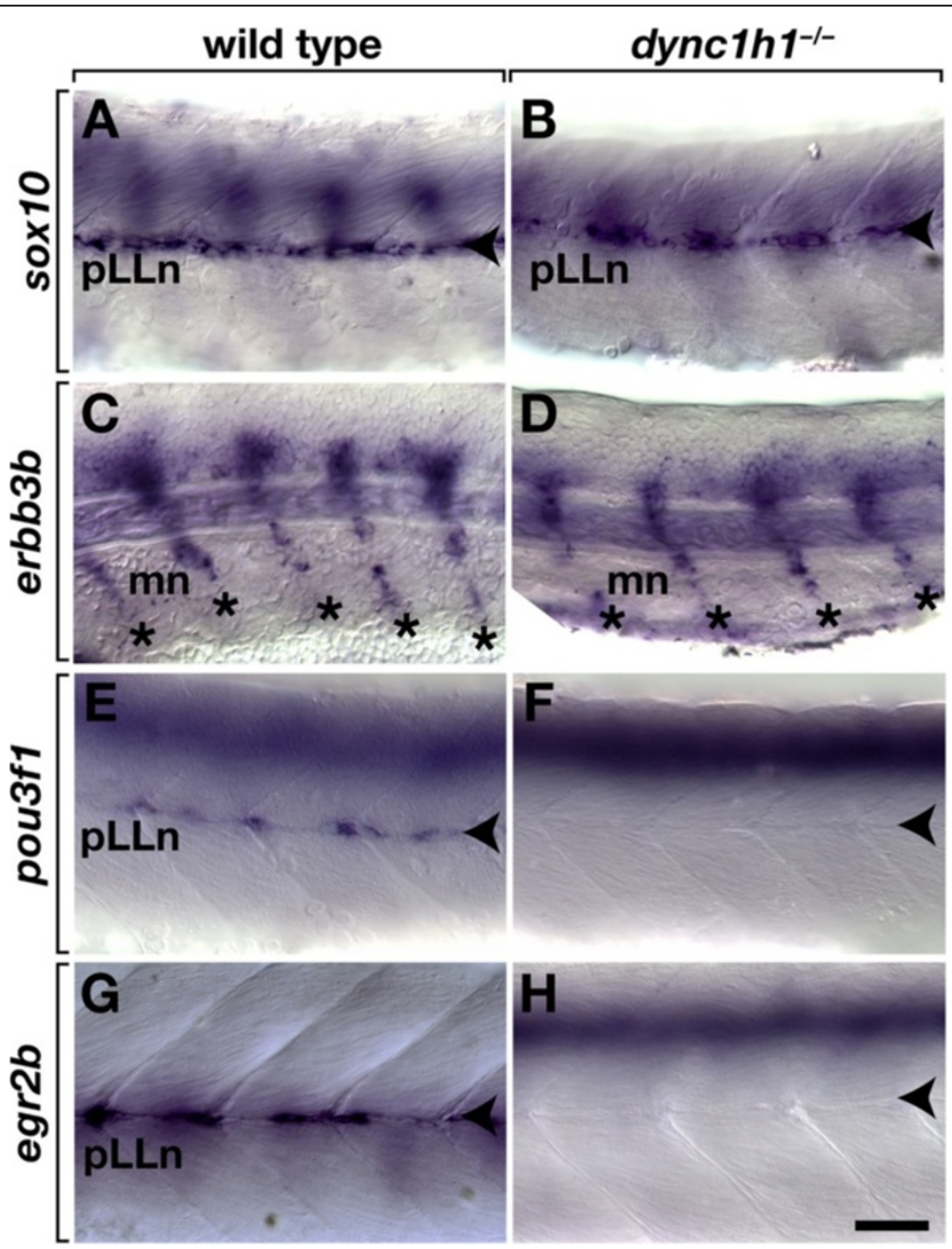

Figure 7 Schwann cells require dync1h1 function to express transcription factors necessary for myelination. sox 10 expression is similar at the pLLn (arrowheads) in 52 hours post fertilization (hpf) wild-type (A) and dync1h1 (B) mutant embryos. Schwann cells associated with motor nerves (mn, asterisks) express erbb3b in both wild-type siblings (C) and dync1h1 mutant (D) embryos 52 hpf. Whereas 52 hpf wild-type embryos express pou3f1 at the pLLn (E), expression is absent or present in only a few cells in dync1h1 mutant embryos (F). At 72 hpf wild-type larva expresses egrab at the pLLn (G), whereas comparably staged dync1h1 mutant larva expresses egr2b in few or no cells $(\mathbf{H})$. Images show lateral views of whole embryos and larvae focused on the mid trunk, with anterior to the left and dorsal up. Scale bar equals $40 \mu \mathrm{m}$. 
was also indistinguishable between wild type and mutant (data not shown). Therefore, dync1h1 mutant embryos express at least some markers of immature Schwann cell progenitors normally. As Schwann cells progress from progenitor to promyelinating states they express pou $3 f 1$, also known as Oct6 and SCIP [18-21]. In wild-type zebrafish embryos pou3f1 expression was evident along the pLLn (Figure 7E). By contrast, mutant embryos $(\mathrm{n}=22)$ and dync1h1 MO-injected embryos $(\mathrm{n}=26)$ consistently had few cells that expressed pouf 31 at the pLLn
(Figure 7F and data not shown). Differentiating Schwann cells express Egr2, also known as Krox20, and Egr2 function is required for myelination [22]. Wild-type zebrafish larvae expressed egr $2 b$ at both motor roots (data not shown) and the pLLn (Figure 7G). In dync1h1 mutants ( $\mathrm{n}=30)$ and dync1h1 MO-injected larvae $(\mathrm{n}=109)$, egr $2 b$ expression was either absent or expressed in very few Schwann cells associated with the pLLn (Figure $7 \mathrm{H}$ and data not shown). By contrast, egr $2 b$ expression was

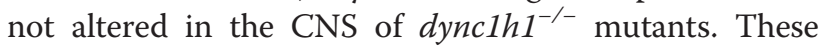
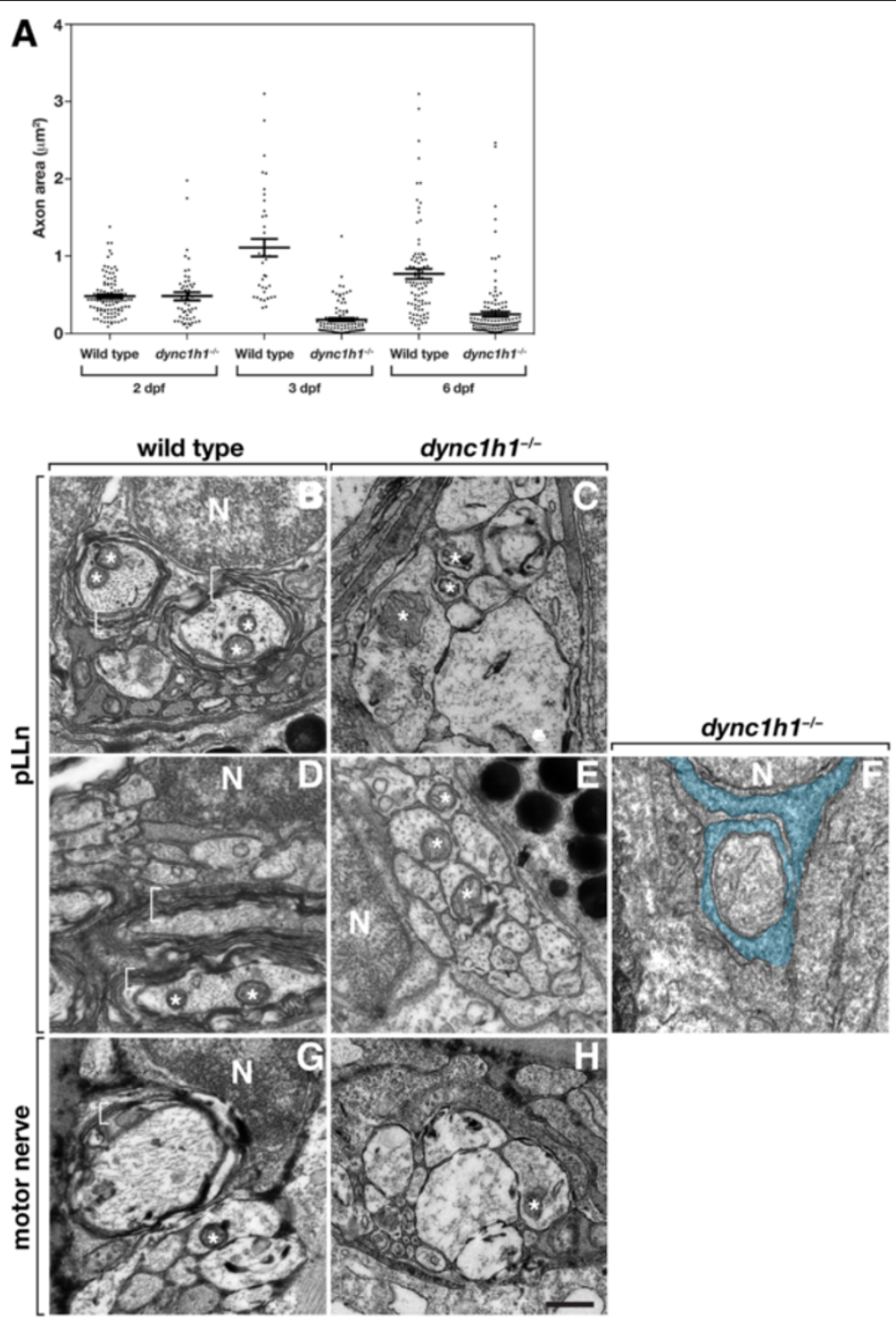

Figure 8 Dync1h1 is required for the formation of myelinating Schwann cells. (A) Scatter plot analysis of axon area. Each point represents one axon. Horizontal bars indicate mean axon area with SD for each group. Panels B-F show transmission electron microscopy (TEM) images of transverse sections through the pLLn, and panels $\mathbf{G}$ and $\mathbf{H}$ show coronal sections through motor nerves. At 3 days post fertilization (dpf), wildtype axons are loosely wrapped by multiple layers of myelin membrane (brackets) (B) whereas in a dync1h1 mutant larva axons are not ensheathed by myelin (C). By 6 dpf myelin membrane is more compact in a wild-type larva (D) but still absent from a mutant larva (E). Panel $\mathbf{F}$ shows an axon wrapped by a single turn of loosely organized Schwann cell membrane (false colored blue). At 4 dpf, myelin ensheaths axon (bracket) of wild-type larvae (G) but is absent from motor axons of a dyncih1 mutant larva (H). Asterisks mark mitochondria, which in mutant axons appear swollen and abnormally shaped. N, Schwann cell nucleus. Scale bar, $0.5 \mu \mathrm{m}$. 
data indicate that dync1h1 is required for Schwann cell progenitors to progress to a mature, myelinating state.

We next investigated the structure of peripheral nerves using transmission electron microscopy (TEM). At $2 \mathrm{dpf}$, dync1h1 mutant embryos had an average of 5.3 axons within each pLLn (ten nerves in five embryos), whereas wild-type embryos had an average of 13.1 axons per pLLn (eight nerves in four embryos). Quantification of mean axon area and analysis of the distribution of axon area revealed no difference between mutant and wild type (Figure 8A). At $3 \mathrm{dpf}$, loosely wrapped myelin membrane was evident on some pLLn axons of wildtype larvae (Figure 8B). By contrast, pLLn axons of mutant larvae were devoid of myelin membrane (Figure 8C). The deficit of axons persisted, with an average of 14.8 axons per pLLn in mutants (six nerves in three larvae) and 36.6 axons per pLLn in wild type (six nerves in three larvae). Additionally, mean axon area was considerably smaller in mutant larvae $\left(0.18 \mu \mathrm{m}^{2}\right)$ compared to wild-type $\left(1.10 \mu \mathrm{m}^{2}\right)$. Scatter plot analysis revealed the presence of more very small axons in mutant compared to wild type (Figure 8A). By $6 \mathrm{dpf}$, the myelin membrane of wild-type larvae appeared more tightly compacted (Figure 8D) but the absence of myelin membrane on axons of mutant larvae persisted (Figure 8E). Although we could identify Schwann cells associated with the nerve, axons frequently did not appear to be wrapped by Schwann cell membrane (Figure 8C, E). However, some axons were wrapped by about 1.0 to 1.5 turns of Schwann cell membrane (Figure 8F). Again, the mean axon area of axons was smaller in mutants $\left(0.24 \mu \mathrm{m}^{2}\right)$ than in wild type $(0.76$ $\mu \mathrm{m}^{2}$ ). Scatter plot analysis revealed that although dync1h1 mutant larvae had some large diameter axons with the pLLn, the distribution was again skewed toward small diameter axons (Figure 8A). Additionally, we noted that mitochondria within mutant axons appeared swollen and irregularly shaped, which can be an indicator of axon degeneration and cell death [23]. We also investigated the structure of motor nerves at $4 \mathrm{dpf}$. Whereas loose myelin membrane was evident in wildtype larvae (Figure 8G), mutant motor nerves had no myelin and mitochondria appeared swollen (Figure $8 \mathrm{H}$ ), similar to the pLLn.

\section{Elevating CAMP in dync1h1 mutant larvae induces myelin gene expression}

Treatment of Schwann cells cultured in the absence of axons with forskolin or cAMP analogs promotes myelin gene expression, indicating that an axon-derived myelination signal is transduced by an adenylyl cyclase/cAMP pathway [24]. Because Dync1h1 can promote signal transduction by transport of signaling endosomes [25], we investigated whether forskolin treatment of dync1h1 mutant larvae could rescue myelin gene expression. Forskolin-treated dync1h1 mutant larvae expressed egr $2 b$ RNA and $m b p$ RNA at both motor nerves and the pLLn comparably to control and forskolin-treated wild-type larvae (Figure 9A-F). Immunohistochemistry revealed that Mbp expression was also restored at both motor nerves and the pLLn (Figure 9G, H). These data indicate that elevation of cAMP level can rescue the myelin gene expression deficit resulting from lack of dync1h1 function, raising the possibility that Dync1h1 promotes myelination by promoting signal transduction necessary for myelination.

\section{Discussion}

Dync1h1 is a subunit of the intracellular motor that transports cargoes on microtubules in a minus enddirected, or retrograde, direction. Cytoplasmic Dynein motors are crucial for a large variety of cellular functions $[26,27]$, including transport of molecules within axons that promote neuron survival [25,28,29]. Accordingly, mutations that disrupt functions of Dynein motor subunits are implicated in axon disease [1]. Although all cells likely require cytoplasmic Dynein motor functions, in peripheral nerve disease disruption of Dynein-mediated transport has only been implicated to affect axons and not other cells that contribute to peripheral nerves, such as myelinating Schwann cells. Here we show that Dync1h1 function is essential for myelination of peripheral nerves in zebrafish.

Because cytoplasmic Dynein had not been previously implicated in peripheral myelination we were surprised to discover that dync1h1 mutant zebrafish larvae did not express peripheral $m b p$, a myelin gene. Schwann cells were present at peripheral axons in mutant larvae, so the lack of $m b p$ expression did not result from absence of Schwann cells. However, the Schwann cells did not wrap axons normally, sometimes ensheathing large diameter axons in only about one turn of Schwann cell membrane, and portions of some large diameter axons were not wrapped by any Schwann cell membrane. Schwann cells of mutant larvae also failed to express pou $3 f I$ and egr $2 b$, which encode transcription factors essential for myelin gene expression. One interpretation of these data is that, in the absence of dync1h1 function, Schwann cells fail to progress from a premyelinating, progenitor state to a fully differentiated, myelinating state.

Consistent with the known role of Dync1h1 in axon transport, peripheral axons in dync1h1 mutant larvae had hallmarks of degeneration. Additionally, mutant larvae had fewer pLLn axons than wild type and mutant axons were, on average, smaller than wild type. Therefore, the failure of myelination could be an indirect consequence of an axonal defect. We attempted to test this 


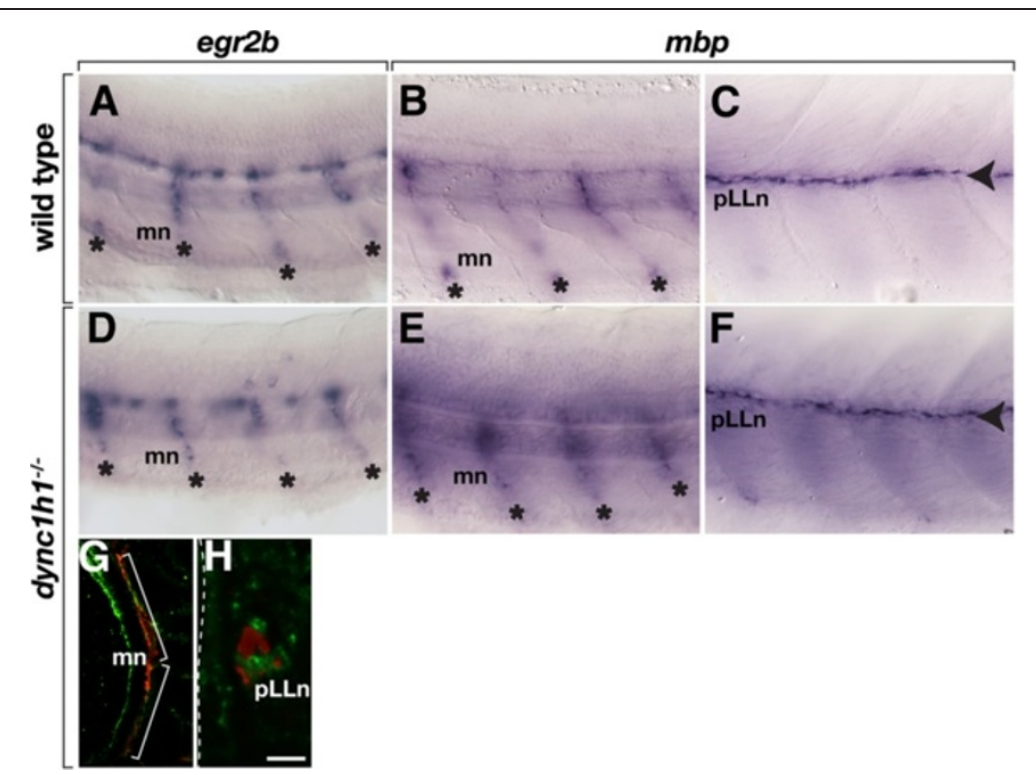

Figure 9 Treatment with forskolin rescues peripheral myelin gene expression in dync $1 h 1$ mutant larvae. Wild-type larvae treated with forskolin express egrab (A) and $m b p$ (B, C) RNA normally at motor nerves ( $m n$, asterisks) and the pLLn (arrowhead). dyncih1 mutant larvae treated with forskolin express egr2b (D) and $m b p(\mathbf{E}, \mathbf{F})$ RNA indistinguishably from wild type. In forskolin-treated dyncih $1^{-/-}$larvae, Schwann cells associated with motor nerve $(\mathbf{G})$ and pLLn axons $(\mathbf{H})$ marked by anti-acetylated tubulin staining (red), express Mbp (green). Images in $\mathbf{A}-\mathbf{F}$ are whole mount views of $3 \mathrm{dpf}$ larvae, anterior to the left and dorsal up. Images in $\mathbf{G}$ and $\mathbf{H}$ are single $\mathbf{z}$-planes captured from transverse sections at $6 \mathrm{dpf}$. Dashed line indicates the lateral edge of the fish. Scale bars equal $20 \mu \mathrm{m}(\mathbf{A}-\mathbf{F}), 40 \mu \mathrm{m}(\mathbf{G})$ and $5 \mu \mathrm{m}(\mathbf{H})$.

possibility by creating different combinations of wildtype and mutant axons and Schwann cells. When we combined wild-type Schwann cells with mutant axons, the Schwann cells expressed Mbp indicating that Dync1h1 function is not required in axons for myelination. We also combined wild-type axons with mutant Schwann cells. In the majority of cases Mbp was either not evident or only present at very low levels. However, in $25 \%$ of the cases in which we analyzed wild-type pLLn axons, the associated mutant Schwann cells appeared to express Mbp at approximately normal levels. We interpret these data to mean that, although Schwann cells lacking Dync1h1 function can express Mbp when in the presence of wild-type axons, Dync1h1 in Schwann cells increases the efficiency and strength of Mbp expression.

If Dync1h1 function within Schwann cells enhances the efficiency of myelination, then stimulation of signaling pathways necessary for myelination might rescue the defects associated with the loss of Dync1h1 function. We tested this by treating mutant larvae with forskolin, which elevates cAMP levels. Whereas rat Schwann cells cultured with axons readily myelinate them, in the absence of axons Schwann cells do not express myelin genes. This requirement for axons can be circumvented by treating Schwann cells with forskolin or cAMP analogs [24]. Elevation of cAMP activates protein kinase A (PKA), and PKA inhibition interferes with myelination [30] indicating that PKA is a necessary component of the signal transduction pathway. A major target of the
cAMP response is Pou3f1/Oct6 [31], which may be activated following PKA phosphorylation of cAMP response element binding protein (CREB) and NF- $\mathrm{kB}$ transcription factors [32,33]. Pou3f1/Oct6 promotes transcription of Egr2/Krox20 [34], which encodes a transcription factor that, with Sox10, drives expression of myelin genes [35-38]. Remarkably, forskolin fully restored egr $2 b$ and mbp expression in dync1h1 mutant larvae, consistent with the possibility that Dync1h1 promotes myelination via a cAMP-dependent pathway.

How might Dync1h1 function in Schwann cells promote myelination? One possibility is that Dync1h1 is required for retrograde transport of signaling molecules from the Schwann cell-axon interface to the nucleus to regulate gene expression. Dynein-mediated retrograde transport of signaling endosomes along axons has been proposed to play key roles in neuron specification, axon outgrowth and neuron survival $[25,28]$. The best known example is internalization and trafficking of Trk receptors following neurotrophin stimulation [39-42] but signaling endosomes appear to contain entire signaling complexes with components of the Ras-MAP kinase, PLCY and PI3 kinase pathways [39-41]. Transcription factors also might be included in signaling endosomes. CREB, translated from axon-localized mRNA in response to NGF, is transported to the cell nucleus to promote neuron survival [43] and nuclear translocation of NF- $\mathrm{K} B$ depends on Dynein function in various cell types [44]. Both CREB and NF-kB promote Schwann cell 
myelination [32,33], making them candidates for factors that that are actively transported within Schwann cells following activation of a cAMP-dependent signaling pathway.

Another possibility is that Dync1h1 is required for signaling by the $G$ protein-coupled receptor (GPCR) Gpr126, which is essential for peripheral myelination in both zebrafish and mice [45,46]. Upon ligand binding, GPCRs stimulate activity of membrane-bound adenylyl cyclase via G proteins, to produce cAMP. Ligand binding also induces GPCR endocytosis and, although this is generally considered to be a mechanism for signal attenuation, in some circumstances cAMP production is enhanced by GPCR endocytosis $[47,48]$. Dynein is important for receptor sorting in early endosomes [49]. Together with the fact that forskolin treatment rescues the myelination defects of both gp126 [45] and dync1h1 mutant larvae, these observations raise the possibility that Dync1h1-mediated internalization and endosomal sorting of Gpr126 is essential for its signaling activity.

Finally, Dync1h1 might facilitate ErbB2/ErbB3 receptor signaling. ErbB receptors and the related EGF receptor are endocytosed upon ligand binding and trafficked through endosomes [50]. In fact, endocytosis and endosomal trafficking can transport ErbB2 to the nucleus of cultured cells [51] where, in principle, it could influence gene expression. Signaling mediated by ErbB2 and ErbB3 receptors promotes Schwann cell proliferation and migration [15]. We found that pLLn Schwann cells of dync1h1 did not increase in number between 3 and 4 dpf as in wild type, and mutant Schwann cells also migrated more slowly and in less direct fashion. These apparently common roles open the possibility that Dync1h1-mediated endosomal trafficking influences ErbB receptor signaling.

\section{Conclusions}

The work reported here shows that Dync1h1, a protein that is required for axon transport and implicated in diseases that affect peripheral axons, is necessary for myelination of peripheral axons by Schwann cells in zebrafish. Our genetic mosaic data provide evidence that efficient myelination requires Dync1h1 function in both Schwann cells and axons. Our observations raise the possibility that mutations of Dync1h1 cause nerve disease, not only by causing damage to axons but also by disrupting formation or maintenance of myelin.

\section{Methods}

\section{Zebrafish husbandry}

The University of Colorado Denver Institutional Animal Care and Use Committee approved all zebrafish studies. Zebrafish stains used include $d y n c 1 h 1^{h i 3684 T g}[8]$
(Amsterdam et al., 2005), $\operatorname{Tg}(m n x 1: G F P)^{m l 2}$ [13],

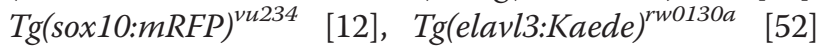
and $\mathrm{AB}$. Embryos produced by paired matings were raised at $28.5^{\circ} \mathrm{C}$, maintained in egg water or embryo medium, and staged according to hpf or dpf. Homozygous mutants for the dync1h $1^{\text {hi3684Tg }}$ allele were created by pair-wise crossings of dync1h1 $1^{\text {hi3684Tg+/- }}$ adults. Embryos younger than $48 \mathrm{hpf}$ were genotyped using Hi3684_5E01: $5^{1}$-AAACCTACAGGTGGGGTCTTTC-3 ${ }^{1}$ and Hi3684_5E02: $5^{1}$-GCTACAACTACGAGCAAGT CAACC $-3^{1}$ as primers for PCR to amplify the mutant dync1h1 $1^{\text {hi3684Tg }}$ allele (protocol available at Zebrafish International Resource Center). A second primer set $5^{1}$-TCTTTAGCGTCGTCCTCCAG- $3^{1}$ and Hi3684_5E02 was used to amplify the wild-type allele.

\section{In situ RNA hybridization}

Experiments were performed as described previously [53]. Probes used include sox10 [10], erbb3 [15], mbp [54], egr2b [55] and pou3f1 [56]. Following in situ hybridization, tissues were fixed with $4 \%$ paraformaldehyde, equilibrated in $70 \%$ glycerol and mounted on glass coverslips for whole-mount imaging. Images were collected using a Zeiss Axio Observer equipped with DIC optics, Retiga Exi digital color camera and Volocity software (Improvision/PerkinElmer). All images were imported into Adobe Photoshop software and image processing was limited to changes in resolution, levels, contrast, brightness and cropping.

\section{Immunohistochemistry}

Embryos and larvae were fixed in $4 \%$ paraformaldehyde, $8 \%$ sucrose, $1 \mathrm{X}$ PBS overnight at $4^{\circ} \mathrm{C}$. For whole-mount immunocytochemistry, embryos and larvae were incubated in $\mathrm{ddH}_{2} \mathrm{O}$ for 4 hours, blocked in PBS-TX (1X PBS, $1 \%$ Triton X) containing 10\% sheep serum and 10\% BSA for 1 hour at room temperature (RT) and incubated in primary antibody diluted in antibody solution $(2 \%$ sheep serum, $2 \%$ BSA, PBS-TX) for 24 hours at $4^{\circ} \mathrm{C}$. After washing several hours in PBS-TX, secondary antibodies diluted in antibody solution were applied for 24 hours at $4^{\circ} \mathrm{C}$. Embryos and larvae were washed in PBSTX for at least 4 hours. For immunocytochemistry on sections, embryos and larvae were embedded in 1.5\% agar $/ 5 \%$ sucrose, frozen with 2-methyl-butane chilled by immersion in liquid nitrogen, and sectioned using a cryostat microtome $(20 \mu \mathrm{m})$. Sections were re-hydrated with $1 \times$ PBS and pre-blocked for 30 minutes in $2 \%$ sheep serum/BSA-1 $\times$ PBS. The sections were incubated with primary antibody overnight at $4^{\circ} \mathrm{C}$, washed extensively with $1 \times$ PBS and incubated with the appropriate fluorescent secondary antibody for 2 hours at RT. Once the secondary antibody was washed off, sections were covered with Vectashield (Vector Laboratories, Burlingame, 
CA, USA). Primary antibodies used were rabbit antiSox10 (1:200) [57], mouse anti-acetylated tubulin (1:5000, catalog T7451, Sigma-Aldrich, St. Louis, MO, USA) and rabbit anti-Mbp (1:200) [12]. Secondary antibodies used were Alexa Fluor 405-, 488- and 568-conjugated goat antirabbit; Alexa Fluor 405- and 568-conjugated goat antimouse (1:200, Life Technologies, Carlsbad, CA, USA).

\section{Transmission electron microscopy}

A t 3, 4, or 6 dpf larvae were anesthetized with Tricaine, placed on ice, and fixed in a solution of $2 \%$ glutaraldehyde, $4 \%$ paraformaldehyde and $0.1 \mathrm{M}$ sodium cacodylate, $\mathrm{pH}$ 7.4. Fixation was accelerated using a Biowave Pro Laboratory Microwave with ColdSpot (Ted Pella, Inc, Redding, CA, USA) maintained at $15^{\circ} \mathrm{C}$. Membranes were enhanced using either secondary fixation with $\mathrm{OsO}_{4}$, uranyl acetate, and imidazole [15], or secondary fixation using $\mathrm{OsO}_{4}-\mathrm{TCH}-\mathrm{OsO}_{4}$. Electron micrographs were collected using a FEI Techai G2 BioTwin microscope, transferred to Adobe Photoshop and image processing was limited to resolution, contrast, and cropping. The axon area and the length of the longest axis of each pLLn axon was measured using Volocity software.

\section{Forskolin treatment}

Embryos were dechorionated and incubated in embryo medium containing $50 \mu \mathrm{M}$ forskolin (F6886, Sigma) dissolved in dimethyl sulfoxide (DMSO). Control embryos were treated with an equal concentration of DMSO ( $0.1 \%$ in embryo medium). Treatments were from 45 to 52 hpf. Following treatment, embryos were placed in embryo medium without drug, fixed at the indicated times, and processed for in situ RNA hybridization or immunohistochemistry.

\section{Genetic mosaic analysis}

Donor embryos were prepared by pair-wise crossing of either $\mathrm{AB}$ or $\operatorname{Tg}(\operatorname{sox} 10: m R F P)$ adults. Host embryos were prepared by pair-wise crossing of either $d y n c 1 h 1^{+/-}$or dync1h1 $1^{+/-;} \operatorname{Tg}(m n x 1: G F P)$ adults. Donor embryos and host embryos at blastula stage were positioned into the molded wells of an agarose plate. Transplantation was performed as previously described [58] with approximately 20 donor cells transplanted into the host embryo. Wild-type $T g(\operatorname{sox} 10: m r f p)$ donors were injected with Alexa488-conjugated 10,000 MW dextran (Invitrogen) at cleavage stage to enable discrimination between donor and host cells. Alternatively, wild-type $\operatorname{Tg}($ elavl3:Kaede) donors were transplanted to $T g(\operatorname{sox} 10: m R F P) ; d y n c 1 h 1^{-/-}$ hosts. At $5 \mathrm{dpf}$, genetic mosaic larvae were fixed, processed for whole-mount immunocytochemistry, and imaged as described above. Larvae with Alexa488 dextran staining in the cell bodies of pLLn neurons or in spinal cord motor neurons, which could contribute wildtype axons to peripheral nerves, were removed from the study and not analyzed for expression of Mbp.

\section{Morpholino injections}

We purchased a previously described antisense Morpholino oligonucleotide (MO) designed to block translation of dynclh1 and consisting of the sequence CGCCGCTGTCAGACATTTCCTACAC [9] from Gene Tools, LLC (Corvallis, OR, USA. The MO was dissolved in water and diluted prior to injections. We injected 1 to $2 \mathrm{~nL}$ into the yolk just below the single cell of fertilized embryos. All MO-injected embryos were raised in embryo medium at $28.5^{\circ} \mathrm{C}$.

\section{Time-lapse imaging}

At $16 \mathrm{hpf}$, embryos were embedded in low melting point agarose and mounted in a heated chamber $\left(28.5^{\circ} \mathrm{C}\right)$ of a motorized stage. Z-stack images were obtained every 10 minutes from 16 to 30 hpf using a PerkinElmer UltraVIEW VoX Confocal System coupled with a Zeiss Axio Observer inverted compound microscope fitted with a 40X oil immersion objective ( $\mathrm{NA}=1.3$ ). Using Volocity software (PerkinElmer, Waltham, MA, USA), images were processed using deconvolution and contrast enhancement. Four-dimensional volumes were assembled at a speed of 6 to 8 time points/second and exported as QuickTime movie files.

\section{Abbreviations \\ CAMP: cyclic adenosine monophosphate; CREB: CAMP response element binding protein; DMSO: Dimethyl sulfoxide; Dpf: Days post fertilization; Dync1h1: Dynein cytoplasmic 1 heavy chain 1; CMT: Charcot-Marie-Tooth; CNS: Central nervous system; GPCR: G protein-coupled receptor; Hpf: Hours post fertilization; Mbp: Myelin basic protein; MEP: Motor axon exit point; MO: Morpholino oligonucleotide; PBS: Phosphate-buffered saline; PCR: Polymerase chain reaction; PKA: Protein kinase A; pLLn: Posterior lateral line nerve; PNS: Peripheral nervous system; RT: Room temperature; SEM: Standard error of the mean; TEM: Transmission electron microscopy; PNS: Peripheral nervous system.}

\section{Competing interests}

The authors declare that they have no competing interests.

\section{Authors' contributions}

MML performed all the experiments described in this manuscript. BA helped design and interpret experiments and wrote the manuscript with MML. Both authors read and approved the final manuscript.

\section{Acknowledgements}

We thank Jimann Shin, Danette Nicolay and members of the Appel lab for advice and discussions; Sarah Casper and Christina Kearns for assistance with experiments; Sarah Kucenas and Will Talbot for providing cDNA clones; JoAnn Buchanan for technical advice and providing the $\mathrm{OsO}_{4}-\mathrm{TCH}$ EM protocol; Dot Dill for electron microscopy technical support, and Wendy Macklin, Laura Opincariu and Christina Kearns for comments on the manuscript. Materials were also provided by the Zebrafish International Resource Center, supported by $\mathrm{NIH-NCRR} \mathrm{grant} \mathrm{P40} \mathrm{RR012546.} \mathrm{The} \mathrm{University} \mathrm{of} \mathrm{Colorado} \mathrm{Denver} \mathrm{Zebrafish}$ Core Facility is supported by NIH grant P30 NS048154. The electron micrographs were generated in the EM core facility of the Department of Cell and Developmental Biology, supported by NIH grant P30 NS048154. This work was supported by NIH Grant RO1 NS062717 and the Gates Frontiers Fund. 
Received: 20 August 2012 Accepted: 6 November 2012 Published: 20 November 2012

\section{References}

1. De Vos KJ, Grierson AJ, Ackerley S, Miller CC: Role of axonal transport in neurodegenerative diseases. Annu Rev Neurosci 2008, 31:151-173.

2. Weedon MN, Hastings R, Caswell R, Xie W, Paszkiewicz K, Antoniadi T, Williams M, King C, Greenhalgh L, Newbury-Ecob R, Ellard S: Exome sequencing identifies a DYNC1H1 mutation in a large pedigree with dominant axonal Charcot-Marie-Tooth disease. Am J Hum Genet 2011, 89:308-312.

3. Puls I, Jonnakuty C, LaMonte BH, Holzbaur EL, Tokito M, Mann E, Floeter MK, Bidus K, Drayna D, Oh SJ, Brown RH Jr, Ludlow CL, Fischbeck KH: Mutant dynactin in motor neuron disease. Nat Genet 2003, 33:455-456.

4. Munch C, Sedlmeier R, Meyer T, Homberg V, Sperfeld AD, Kurt A, Prudlo J, Peraus G, Hanemann CO, Stumm G, Ludolph AC: Point mutations of the p150 subunit of dynactin (DCTN1) gene in ALS. Neurology 2004, 63:724-726

5. Chen X-J, Levedakou EN, Millen KJ, Wollmann RL, Soliven B, Popko B: Proprioceptive sensory neuropathy in mice with a mutation in the cytoplasmic Dynein heavy chain 1 gene. J Neurosci 2007, 27:14515-14524.

6. Ilieva HS, Yamanaka K, Malkmus S, Kakinohana O, Yaksh T, Marsala M Cleveland DW: Mutant dynein (Loa) triggers proprioceptive axon loss that extends survival only in the SOD1 ALS model with highest motor neuron death. Proc Natl Acad Sci USA 2008, 105:12599-12604

7. Dupuis L, Fergani A, Braunstein KE, Eschbach J, Holl N, Rene F, Gonzalez De Aguilar J-L, Zoerner B, Schwalenstocker B, Ludolph AC, Loeffler J-P: Mice with a mutation in the dynein heavy chain 1 gene display sensory neuropathy but lack motor neuron disease. Exp Neurol 2009, 215:146-152.

8. Amsterdam A, Nissen RM, Sun Z, Swindell E, Farrington S, Hopkins N: Submission and curation of data from an insertional mutagenesis screen. ZFIN Direct Data Submission 2005.

9. Insinna C, Baye LM, Amsterdam A, Besharse JC, Link BA: Analysis of a zebrafish dync1h1 mutant reveals multiple functions for cytoplasmic dynein 1 during retinal photoreceptor development. Neural Dev 2010, 5:12

10. Dutton KA, Pauliny A, Lopes SS, Elworthy S, Carney TJ, Rauch J, Geisler R, Haffter $P$, Kelsh RN: Zebrafish colourless encodes sox10 and specifies non-ectomesenchymal neural crest fates. Development 2001, 128:4113-4125.

11. Kuhlbrodt K, Herbarth B, Sock E, Hermans-Borgmeyer I, Wegner M: Sox10, a novel transcriptional modulator in glial cells. J Neurosci 1998, 18:237-250.

12. Kucenas S, Wang WD, Knapik EW, Appel B: A selective glial barrier at motor axon exit points prevents oligodendrocyte migration from the spinal cord. J Neurosci 2009, 29:15187-15194.

13. Flanagan-Steet H, Fox MA, Meyer D, Sanes JR: Neuromuscular synapses can form in vivo by incorporation of initially aneural postsynaptic specializations. Development 2005, 132:4471-4481.

14. Jessen KR, Mirsky R: The origin and development of glial cells in peripheral nerves. Nat Rev Neurosci 2005, 6:671-682.

15. Lyons DA, Pogoda HM, Voas MG, Woods IG, Diamond B, Nix R, Arana N, Jacobs J, Talbot WS: erbb3 and erbb2 are essential for schwann cell migration and myelination in zebrafish. Curr Biol 2005, 15:513-524.

16. Barrallo-Gimeno A, Holzschuh J, Driever W, Knapik EW: Neural crest survival and differentiation in zebrafish depends on mont blanc/tfap2a gene function. Development 2004, 131:1463-1477.

17. Lister JA, Cooper C, Nguyen K, Modrell M, Grant K, Raible DW: Zebrafish Foxd3 is required for development of a subset of neural crest derivatives. Dev Biol 2006, 290:92-104.

18. Arroyo EJ, Bermingham JR Jr, Rosenfeld MG, Scherer SS: Promyelinating Schwann cells express Tst-1/SCIP/Oct-6. J Neurosci 1998, 18:7891-7902.

19. Blanchard AD, Sinanan A, Parmantier E, Zwart R, Broos L, Meijer D, Meier C, Jessen KR, Mirsky R: Oct-6 (SCIP/Tst-1) is expressed in Schwann cell precursors, embryonic Schwann cells, and postnatal myelinating Schwann cells: comparison with Oct-1, Krox-20, and Pax-3. J Neurosci Res 1996, 46:630-640.

20. Scherer SS, Wang DY, Kuhn R, Lemke G, Wrabetz L, Kamholz J: Axons regulate Schwann cell expression of the POU transcription factor SCIP. J Neurosci 1994, 14:1930-1942.

21. Zorick TS, Syroid DE, Arroyo E, Scherer SS, Lemke G: The transcription factors SCIP and Krox-20 mark distinct stages and cell fates in Schwann cell differentiation. Mol Cell Neurosci 1996, 8:129-145.
22. Topilko P, Schneider-Maunoury S, Levi G, Baron-Van Evercooren A, Chennoufi AB, Seitanidou T, Babinet C, Charnay P: Krox-20 controls myelination in the peripheral nervous system. Nature 1994, 371:796-799.

23. Norenberg MD, Rao KVR: The mitochondrial permeability transition in neurologic disease. Neurochem Int 2007, 50:983-997.

24. Morgan L, Jessen KR, Mirsky R: The effects of cAMP on differentiation of cultured Schwann cells: progression from an early phenotype (04+) to a myelin phenotype (P0+, GFAP-, N-CAM-, NGF-receptor-) depends on growth inhibition. J Cell Biol 1991, 112:457-467.

25. Cosker KE, Courchesne SL, Segal RA: Action in the axon: generation and transport of signaling endosomes. Curr Opin Neurobiol 2008, 18:270-275.

26. Allan VJ: Cytoplasmic dynein. Biochem Soc Trans 2011, 39:1169-1178.

27. Hunt SD, Stephens DJ: The role of motor proteins in endosomal sorting. Biochem Soc Trans 2011, 39:1179-1184.

28. Zweifel LS, Kuruvilla R, Ginty DD: Functions and mechanisms of retrograde neurotrophin signalling. Nat Rev Neurosci 2005, 6:615-625.

29. Wu C, Cui B, He L, Chen L, Mobley WC: The coming of age of axonal neurotrophin signaling endosomes. J Proteomics 2009, 72:46-55.

30. Howe DG, McCarthy KD: Retroviral inhibition of CAMP-dependent protein kinase inhibits myelination but not Schwann cell mitosis stimulated by interaction with neurons. J Neurosci 2000, 20:3513-3521.

31. Monuki ES, Weinmaster G, Kuhn R, Lemke G: SCIP: a glial POU domain gene regulated by cyclic AMP. Neuron 1989, 3:783-793.

32. Mandemakers W, Zwart R, Jaegle M, Walbeehm E, Visser P, Grosveld F, Meijer D: A distal Schwann cell-specific enhancer mediates axonal regulation of the Oct- 6 transcription factor during peripheral nerve development and regeneration. EMBO J 2000, 19:2992-3003.

33. Nickols JC, Valentine W, Kanwal S, Carter BD: Activation of the transcription factor NF-kappaB in Schwann cells is required for peripheral myelin formation. Nat Neurosci 2003, 6:161-167.

34. Ghislain J, Charnay P: Control of myelination in Schwann cells: a Krox20 cis-regulatory element integrates Oct6, Brn2 and Sox10 activities. EMBO Rep 2006, 7:52-58.

35. Denarier E, Forghani R, Farhadi HF, Dib S, Dionne N, Friedman HC, Lepage $P$, Hudson TJ, Drouin R, Peterson A: Functional organization of a Schwann cell enhancer. J Neurosci 2005, 25:11210-11217.

36. Farhadi HF, Lepage P. Forghani R, Friedman HC, Orfali W, Jasmin L, Miller W Hudson TJ, Peterson AC: A combinatorial network of evolutionarily conserved myelin basic protein regulatory sequences confers distinct glial-specific phenotypes. J Neurosci 2003, 23:10214-10223.

37. Forghani R, Garofalo L, Foran DR, Farhadi HF, Lepage P, Hudson TJ, Tretjakoff I, Valera P, Peterson A: A distal upstream enhancer from the myelin basic protein gene regulates expression in myelin-forming schwann cells. J Neurosci 2001, 21:3780-3787.

38. Jones EA, Jang SW, Mager GM, Chang LW, Srinivasan R, Gokey NG, Ward RM, Nagarajan R, Svaren J: Interactions of Sox10 and Egr2 in myelin gene regulation. Neuron Glia Biol 2007, 3:377-387.

39. Delcroix JD, Valletta JS, Wu C, Hunt SJ, Kowal AS, Mobley WC: NGF signaling in sensory neurons: evidence that early endosomes carry NGF retrograde signals. Neuron 2003, 39:69-84.

40. Howe CL, Valletta JS, Rusnak AS, Mobley WC: NGF signaling from clathrincoated vesicles: evidence that signaling endosomes serve as a platform for the Ras-MAPK pathway. Neuron 2001, 32:801-814.

41. Ye H, Kuruvilla R, Zweifel LS, Ginty DD: Evidence in support of signaling endosome-based retrograde survival of sympathetic neurons. Neuron 2003, 39:57-68.

42. Heerssen HM, Pazyra MF, Segal RA: Dynein motors transport activated Trks to promote survival of target-dependent neurons. Nat Neurosci 2004, 7:596-604

43. Cox $\sqcup$, Hengst U, Gurskaya NG, Lukyanov KA, Jaffrey SR: Intra-axonal translation and retrograde trafficking of CREB promotes neuronal survival. Nat Cell Biol 2008, 10:149-159.

44. Shrum CK, Defrancisco D, Meffert MK: Stimulated nuclear translocation of NF-kappaB and shuttling differentially depend on dynein and the dynactin complex. Proc Natl Acad Sci USA 2009, 106:2647-2652

45. Monk KR, Naylor SG, Glenn TD, Mercurio S, Perlin JR, Dominguez C, Moens CB, Talbot WS: A G protein-coupled receptor is essential for Schwann cells to initiate myelination. Science 2009, 325:1402-1405.

46. Monk KR, Oshima K, Jörs S, Heller S, Talbot WS: Gpr126 is essential for peripheral nerve development and myelination in mammals. Development 2011, 138:2673-2680. 
47. Calebiro D, Nikolaev VO, Persani L, Lohse MJ: Signaling by internalized G-protein-coupled receptors. Trends Pharmacol Sci 2010, 31:221-228.

48. Jalink K, Moolenaar WH: G protein-coupled receptors: the inside story. Bioessays 2010, 32:13-16.

49. Driskell OJ, Mironov A, Allan VJ, Woodman PG: Dynein is required for receptor sorting and the morphogenesis of early endosomes. Nat Cell Biol 2007, 9:11-120.

50. Sorkin A, Goh LK: Endocytosis and intracellular trafficking of ErbBs. Exp Cell Res 2009, 315:683-696.

51. Giri DK, Ali-Seyed M, Li L-Y, Lee D-F, Ling P, Bartholomeusz G, Wang S-C, Hung M-C: Endosomal transport of ErbB-2: mechanism for nuclear entry of the cell surface receptor. Mol Cell Biol 2005, 25:11005-11018.

52. Sato T, Takahoko M, Okamoto H: HuC:Kaede, a useful tool to label neural morphologies in networks in vivo. Genesis 2006, 44:136-142.

53. Hauptmann G, Gerster T: Multicolor whole-mount in situ hybridization. Methods Mol Biol 2000, 137:139-148.

54. Brosamle C, Halpern ME: Characterization of myelination in the developing zebrafish. Glia 2002, 39:47-57.

55. Oxtoby $\mathrm{E}$, Jowett $\mathrm{T}$ : Cloning of the zebrafish krox-20 gene (krx-20) and its expression during hindbrain development. Nucleic Acids Res 1993, 21:1087-1095.

56. Hauptmann G, Soll I, Gerster T: The early embryonic zebrafish forebrain is subdivided into molecularly distinct transverse and longitudinal domains. Brain Res Bull 2002, 57:371-375.

57. Park HC, Boyce J, Shin J, Appel B: Oligodendrocyte specification in zebrafish requires notch-regulated cyclin-dependent kinase inhibitor function. J Neurosci 2005, 25:6836-6844.

58. Carmany-Rampey A, Moens CB: Modern mosaic analysis in the zebrafish. Methods 2006, 39:228-238.

doi:10.1186/1749-8104-7-37

Cite this article as: Langworthy and Appel: Schwann cell myelination requires Dynein function. Neural Development 2012 7:37.

\section{Submit your next manuscript to BioMed Central and take full advantage of:}

- Convenient online submission

- Thorough peer review

- No space constraints or color figure charges

- Immediate publication on acceptance

- Inclusion in PubMed, CAS, Scopus and Google Scholar

- Research which is freely available for redistribution 